\title{
Research of the Dynamical Model and University Library's Role in the Property Alleviation
}

\section{Duyi He}

Moro Library, Leshan Normal University, Leshan, China

Email: qiangjianglsnu@outlook.com

How to cite this paper: He, D. Y. (2021). Research of the Dynamical Model and University Library's Role in the Property Alleviation. Open Journal of Social Sciences, 9, 387-395.

https://doi.org/10.4236/jss.2021.93025

Received: January 28, 2021

Accepted: March 26, 2021

Published: March 29, 2021

Copyright $\odot 2021$ by author(s) and Scientific Research Publishing Inc. This work is licensed under the Creative Commons Attribution International License (CC BY 4.0).

http://creativecommons.org/licenses/by/4.0/

\section{(c) (i) Open Access}

\begin{abstract}
Poverty eradication is one of the three major battles in our country at the present stage and is a common subject for world development. It is the key to study the dynamic evolution model from poverty, poverty alleviation to wealth. This paper analyzes the causes of poverty from macro to micro, from the regional breadth, and extracts ten factors of poverty. Combined with the dynamic evolution model, this paper puts forward that "root" culture is the key to prevent the return to poverty and realize the stable eradication of poverty, and puts forward the strategy of cultivating the "root" culture of the poor people in the university library, which is of great significance for the realization of stable poverty alleviation in our country.
\end{abstract}

\section{Keywords}

Poverty Alleviation, Culture of Poverty, Root Support, Evolutionary Model

\section{Introduction}

Poverty is not the representative of human civilization and development, nor is it the embodiment of a well-off life. China cannot achieve the strategic goal of a well-off society with poverty. Global development also regards poverty eradication as one of the important tasks of governments in governing the country. According to the World Bank, poverty is defined as living on less than $\$ 1.9$ a day (World Bank Open Data, https://data.worldbank.org.cn/), defined as the poor. According to World Bank statistics for December 2019, by the end of 2015, the world's poor accounted for $10 \%$ of the world's poor (World Bank Open Data, https://data.worldbank.org.cn/), and the poor were mainly concentrated in East Asia, South Asia and sub-Saharan Africa. 
Poverty proportion, living on less than $\$ 1.9$

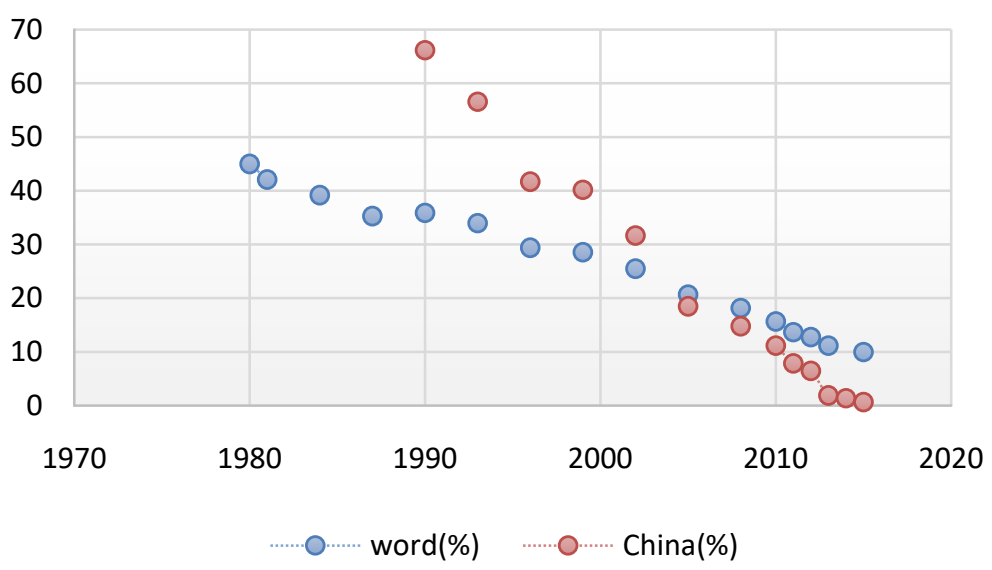

Figure 1. The compare of poverty ratio between the world and China (World Bank Open Data, https://data.worldbank.org.cn/).

Figure 1 shows the annual changes of the world and China's poor from the World Bank. The data show that the global extreme poverty rate fell from about 36 per cent to 10 per cent between 1990 and 2015. Among them, China's extreme poverty rate fell from $67 \%$ in 1990 to $0.7 \%$ in 2015 . The global poverty population as a whole shows a marked downward trend, and our country is now approaching poverty eradication.

In order to carry out the poverty alleviation policy more effectively and form the stable poverty alleviation effect in our country, many literatures have analyzed the causes of poverty, the path of poverty alleviation and the poverty alleviation policy from different angles. Literatures from the causes of poverty, the mechanism, China's poverty alleviation policy, precision poverty alleviation existing difficulties and other aspects, it is concluded that the formulation of precision poverty alleviation to provide reference. Document (Zhang, 2019; Yang, 2019), from the perspective of university library, this paper analyzes the present situation and difficulties of university library in precision poverty alleviation, and discusses the importance of cultural poverty alleviation. On this basis, this paper abstracts the dynamic evolution model of poverty, poverty and wealth, and vividly shows the following core task of poverty alleviation work, that is, the cultivation of root culture in poor areas.

\section{Causes of Poverty}

\subsection{Primary Classification of Causes of Poverty}

Poverty eradication is a world issue, although the world is developing, the overall decline in poverty, But according to the World Bank, Sub-Saharan South Africa, Poverty continues to increase. To effectively eradicate poverty, Analysis of the causes of poverty is the key. Yang Long and Li Meng analyzed the causes of poverty from three aspects: natural environment, social factors and individual factors, The object of the analysis is the farmers in the poor areas, Get the natu- 
ral conditions under bad conditions farmers are difficult to obtain good resources and poverty and many other good views (Yang \& Li, 2017). Wang Qiang's indepth study of the endogenous dynamics of poverty, the endogenous dynamics model. Through the rural panel data of China 2014-2016, the relationship between the endogenous power of poverty eradication and the depth of poverty, the time of poverty, financial support and industrial support, has provided the theory support (Wang, 2020) to carry out the poverty alleviation work. This article will be from the regional economic development, from face to point, from outside to inside to explore the causes of poverty. The causes of poverty are primary classified by breadth, as shown in Figure 2, Can be divided into three categories, That is, regional poverty, local poverty and individual poverty. The map can also be explained by the breadth of causes leading to poverty, Like when new China was founded, The country is in the most difficult period of economic development, This situation is extremely prone to widespread poverty. Sub-Saharan Africa is currently the world's most impoverished region, Is in a large regional state of poverty. China's "three districts and three states" poverty is relatively concentrated, by the end of 2019, there were still 1.72 million poor (Chen, 2019), this is local poverty in our country, it only exists in a certain area. As for the individual poverty referred to here, which includes surrounding the area is not poor, including a very small number of poor households remaining among farmers, such poverty is a very small and isolated phenomenon.

\subsection{Secondary Indicators of Causes of Poverty}

Continue to analyze the causes of these three types of poverty, you can get the second-level poverty indicators shown in Figure 3 a total of 10. The regional poverty focuses on the economic environment inside and outside the region.

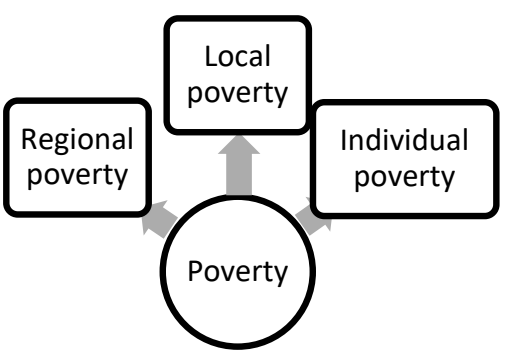

Figure 2. The regional classify of poverty.
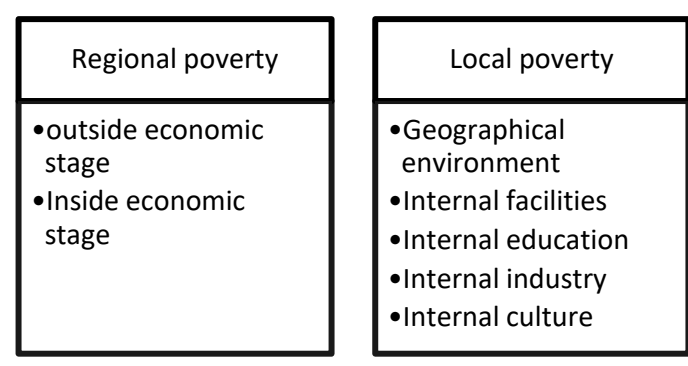

Individual poverty

-Physical condition

-Educational level

-Individual culture

Figure 3. The second factors of poverty. 
This kind of large-scale poverty belongs to the factors of macroeconomic development strategy, so we should find a solution from the development strategy. For example, sub-Saharan Africa and South Asia are the regions with the most concentrated poverty in the world and the largest regional poverty. The root cause of poverty is the poor internal and external economic environment.

Local poverty can be divided into five types of poverty factors, that are the geographical environment, facilities, educational conditions, industrial conditions and cultural environment, and all these are regional internal factors. These five aspects have certain internal relation. The geographical environment is the consideration of the natural environment of the local poverty areas, such as plains, hills, mountains, remote areas, tropical and high-cold zones; facilities contain transportation and living conditions, which are directly related to the people's life; educational conditions refer to the educational resources available in the poor areas and the education of children of appropriate age; industrial conditions refer to whether the area has the relevant conditions for industrial development; and cultural environment refers to the character culture of the poor areas, such as humanities, enterprising, self-reliance, self-reliance and hard struggle, whether it is the character of the general working masses. For example, in some areas, the common people generally like to play Mahjong, some local people like sports, some local people like labor, some places lazy wind, do not seek to advance, and so on, each place has the particularity of the region. Local poverty should be promoted according to the causes of poverty in various regions.

Here mainly from the poor individual analysis of the causes of poverty, mainly including three aspects, physical condition, education level and individual cultural thinking. Some have physical disabilities that lead to difficulties in production, life and make them poor; some have low levels of education and lack of ability to lead to poverty; some have good health, have the ability to improve living conditions and have the ability to engage in production, but cultural thinking is wrong, and for a long time has formed the "waiting, reliable and asking" cultural thought of poverty, which is widespread in local poverty and individual poverty, which is the "root" we will talk about below.

Although we summarize these ten secondary poverty indicators from macro to point, they are different and closely related. Individual poverty thought will also exist in local poverty and regional poverty at the same time, and individual poverty may also contain the factors of local poverty, and various poverty factors interact to aggravate the occurrence and development of poverty. If the thought of individual poverty is not corrected in time, it will form a culture of poverty on a large scale, and there will be a large area of poverty, even economic recession, otherwise, "the country is rich and the people are strong".

\section{Poverty Reduction Strategies}

\subsection{Regional Poverty Reduction Strategies}

Absolute poverty, relative poverty, structure poverty and spatial poverty are the common types (Olojede \& Osah, 2020). In this article according to Chinese po- 
verty process, regional poverty is the first status of poor. In the final, the division of the poor population is mainly based on the economic indicators, according to the analysis of the causes of poverty, when poverty is in different types and breadth, different governance strategies should be adopted. Prior to 2001, China's poverty rate was very high ( $\mathrm{He}$ et al., 2021), belonging to the period of poverty in large regions. Poverty alleviation need deep cooperation between various parties, find more effective strategy (Larantika et al., 2017). It examined the potentials and benefits of information and communication as a way to poverty alleviation in Nigeria (Adeniji, 2010). In china in order to get rid of poverty, the country adopted a strategy to speed up the development of its economy. By 2010, China's total economy had leapt to the second place in the world, and the rate of the poor population had also from 67 percent in 1990 to 11 percent in 2010. Economic development has achieved the general decline of the poor, but also laid a strong foundation for the follow-up work.

\subsection{Local Poverty Reduction Policies}

Since the 18th National Congress, Chinese government have attached great importance to poverty alleviation. At this time, poverty is local poverty, focusing on the "Three Districts and Three Continents" and other areas. The secretary's footprint went all over the deep poverty areas and put forward the requirement that poverty alleviation should be as accurate as embroidery. President Xi proposed the poverty reduction thought of "Seeking truth from facts, Adapting measures to local conditions, Classifying guidance, and Poverty support with precision" afterward Hunan inspection in 2013 (Zhang, 2019). All local governments formulated and implemented precision poverty alleviation in accordance with the spirit of the Central Committee, must do well as "Precision identification, precision help, precision strategy, precision assessment”. The work of precision poverty alleviation is to grasp the causes of poverty in each poverty point accurately, and then to give precise measures, so the work of poverty alleviation has achieved remarkable results, and more than 10 million poor people are lifted out of poverty every year.

\subsection{Individual Poverty Alleviation Measures}

After many years of accurate poverty alleviation, there are only more than 10 million poor people in China after 2018. This period can be classified as an individual poverty period. There is poverty in only a few regions of the country, and the causes of poverty include local poverty at the same time. For achieving the goal of building a well-off society in our country by 2020, the State Council issued "the Guidance on Three Years of Action to Win the Fight against Poverty" in the central to local, to achieve one-help-one poverty relief policy, take a variety of measures to solve the problem of poverty. For example, in Liangshan Yi nationality area, the causes of poverty include backward education and culture, difficult transportation and living conditions in mountainous areas, and blocked 
economic development. To improve this, the state and local governments raised a large amount of funds to build roads and houses, to solve traffic and living conditions. Peace education is a way to proper people towards the path of correction (Ghanta, 2021), Improving the poor's overall quality through education is an important way in China (Yong and Zhang, 2021). To build or rebuild all kinds of primary and secondary school buildings, improve the conditions for running schools, recruit teachers to support Liangshan's education in Sichuan Province, solve cultural and ideological problems, and promote the cultural accomplishment of the common people in the region. It is understood that Leshan normal University alone sent more than 70 teachers to Leibo County per year, greatly alleviated the problem of lack of teachers.

In general, China's poverty alleviation policy ideas are in three steps, step 1 is reform and opening up to achieve a small-scale poverty eradication, and let some people get rich first, in order to drive others to get rich; Step 2 is after joining the WTO, the reform continued to deepen and the scope of reform expanded. Realize poverty reduction in masses; Step 3 is the accurate poverty alleviation adopted since the 18th National Congress, elimination of local and individual poverty, and to the end achieving a comprehensive well-off society. Making a huge contribution to the task of eradicating poverty in the world.

\section{Dynamic Evolution Model of Poverty}

\subsection{The Root of Poverty Alleviation}

As the ancient Chinese saying goes "to cure the disease must cure it's root", poverty alleviation is the way for the country to cure the poverty disease. The opinion on the implementation of the strategy of rural revitalization issued in January 2018 emphasizes the need to stimulate the endogenous motivation of the poor to ensure the stability of the out of poverty (The Committee of Course Edition Group, 2019). The root here is poverty-culture, which the factor that affects the endogenous motive force. The culture here is not only a simple problem of understanding words, but also the essence of Chinese civilization, "self-reliance, hard struggle, self-esteem and self-improvement". The deepest part of our poverty alleviation is to support this root and let this culture take root in the hearts of the poor.

\subsection{Dynamic Evolution Model of Poverty Propose}

The year 2020 is the end of year for China to eradicate poverty and build a well-off society in our country. The dynamic relationship between poverty and prosperity is extracted here, as shown in Figure 4. The model proposed is according to massive social investigations in poverty households, individual poverty households stand there waiting for government help in some poverty regional area. In this model contains three parts, poverty, poverty eradication and enrichment. Poor households can achieve poverty eradication under external support, and external support will be removed after poverty eradication. At this time, the economic situation of farmers after poverty eradication will have two 


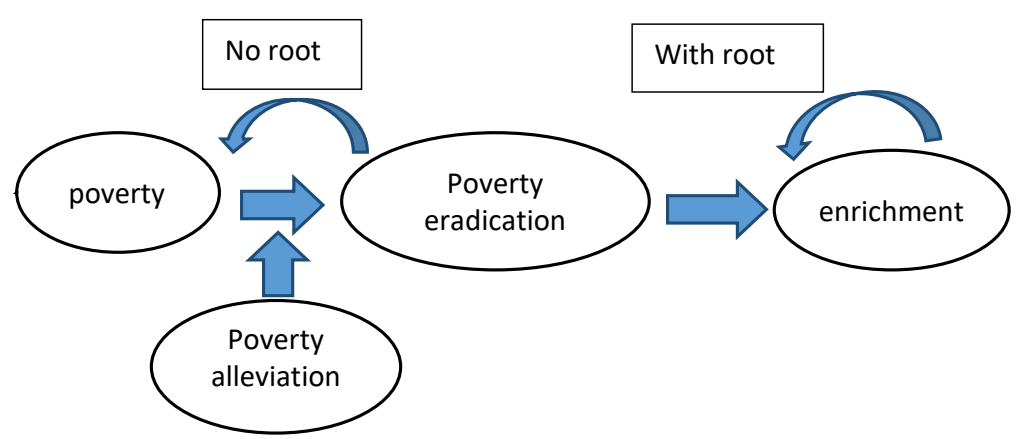

Figure 4. The dynamic model of root alleviation and poverty alleviation.

evolutionary directions, enrichment or return to poverty. What plays a decisive role in this process is the "root" mentioned in this paper. The rootless wood will die and the rootless farmers will return to poverty. On the other hand, the root of the wood grows rapidly, the "root" farmers will enter the healthy development track of becoming rich, life is better, so poverty alleviation should support the root. Through education arrive at poverty alleviation forever is the most stability.

\section{The Mission of Poverty Alleviation of University Library}

Colleges and universities should not only train qualified talents for the country, create knowledge for the development of human civilization, but also actively participate in serving social and local development and actively devote themselves to the national strategy. The key of eliminate poverty is helping the root. How to effectively cultivate the culture of helping the root is a new problem to be solved on the road of poverty alleviation.

\subsection{The Statement of University Library Participate Poverty Alleviation}

At the present stage, the main ways of participating in poverty alleviation work in university libraries are shallow and not deep, mainly in the form of donation, sending books to the countryside, reading promotion and so on. These forms are not deep into the root of culture, with little effect. Yang Liying proposed to provide equal cultural information services for citizens, open information resources services and other ideas (Yang, 2019), Zhang Zhuwin put forward the cultural objectives, cultural projects, cultural service products and other cultural accurate identification, and then formulate a supporting cultural poverty alleviation management mechanism (Zhang, 2019) cultural poverty alleviation path. These ideas are beneficial to the development of cultural poverty alleviation.

\subsection{The Task of University Library in the Model}

The goal of the action is to cultivate the strong desire of poor households to get rid of poverty, to build up the confidence that they can get rid of poverty. How to achieve this goal can take the following strategies as shown Figure 5.

University library experts go deep into poor villages to understand the current 


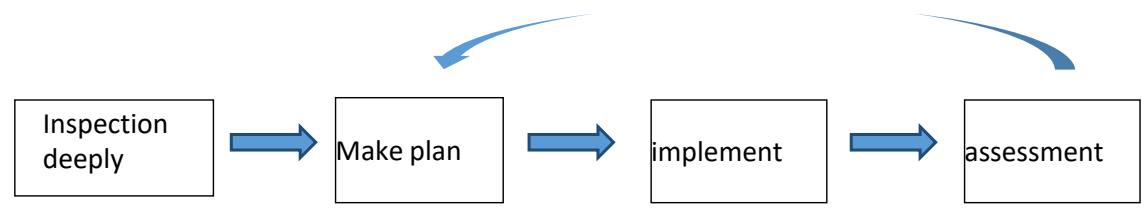

Figure 5. University library support root strategy.

situation of poverty eradication, natural environment, living and production conditions, local folk customs, analyse the causes of poverty, feel the depth and breadth of the impact of local poverty culture, and form a detailed investigation report. According to the research report, the library held a special meeting to study the cultural requirements of the standard support root to formulate a feasible work plan. According to the requirements of the program, the corresponding team of cultural and educational experts should be sent to the poverty point, carry out the program, carry out the educational activities continuously, make it abandon the poor culture and cultivate its root culture. In order to ensure the effect, the object tracking should be carried out regularly, the quality of education should be detected, the problem analysis of the substandard index should be carried out, and the work plan should be dynamically adjusted until it is fully up to the standard. Fundamentally solve the internal factors of poverty, so that farmers from poverty to become rich.

\section{Conclusion}

This paper analyzes the causes of poverty from macro to micro, proposes the dynamic evolution model from poverty to becoming rich, puts forward the key to helping the root, and puts forward some thoughts for the long-term and stable development of human society. The focus is on how to solve the development of poverty-stricken areas in the post-poverty-alleviation era. China is also actively helping other countries reduce poverty through Belt and Road. However, how to eliminate poverty culture, cultivate the people's "self-improvement, self-reliance, hard struggle, hard work" thought, to help the "root" of development, education play an important role. The university library is the treasure house of wisdom and the ocean of knowledge. It is our new responsibility and mission to bear the responsibility of cultural inheritance and cultural service.

\section{Acknowledgements}

This research was financially supported by Leshan science and technology bureau foundation (No. 19NZD067) and the Sichuan Education Department Foundation (No. 18ZB0273).

\section{Conflicts of Interest}

The author declares no conflicts of interest regarding the publication of this paper.

\section{References}

Adeniji, O. (2010). Potentials of Information and Communication Technologies for Po- 
verty Alleviation and Food Security. Journal of Agricultural Extension, 14, 130-138. https://doi.org/10.4314/jae.v14i2.64129

Chen, S. J. (2019). Practical Difficulties and Path Selection of Targeted Poverty Alleviation in Ethnic Areas in the New Era. Journal of Jiyuan Vocational and Technical College, $18,10-14$.

Ghanta, B. (2021). Need of Peace Education in Higher Education in Mekong-Ganga Cooperation Countries. UGC Care Journal, 43, 162-168.

He, Y. T., Wang, S., Chen, L., Wei, M., \& Zhang, P. Y. (2021). Comparative Study between Fiscal Poverty Alleviation and Financial Poverty Alleviation in Tibetan Areas of Sichuan Province. Advances in Economics, Business and Management Research, 165, 54-60.

Larantika, A. A. A. D., Zauhar, S., Makmur, M., \& Setyowati, E. (2017). Collaboration as a Strategy for Poverty Alleviation. International Journal of Social Sciences and Humanities, 1, 40-48.

Olojede, I. B., \& Osah, G. (2020). Political Corruption and Human Security in Nigeria. RUJMASS, 6, 11-21.

The Committee of Course Edition Group (2019). Fight with Build a Well-Off Society in Our Country. Beijing: The People Publish Society, 132-133.

The World Bank Open Data. https://data.worldbank.org.cn/

Wang, Q. (2020). An Empirical Study of the Endogenous Poverty-Alleviation Motivation of the Poverty-Stricken Groups and its Influencing Factors Based on the 2014-2016 Panel Data of China's Rural Poor Families. Journal of Yunnan Minzu University (Social Sciences), 37, 90-99.

Yang, L. Y. (2019). Exploring the Ways of Realizing the Social Function of Library Participating in Cultural Precision. Journal of Suihua University, 39, 128-130.

Yang, L., \& Li, M. (2017). Research on the Causes and Mechanism of Poverty-With Comments on the Policy of Poverty Alleviation in China. Journal of South China Normal University (Social Science Edition), No. 4, 33-40.

Yong, M., \& Zhang, Y. (2021). Poverty Alleviation by Education: Exploration and Experience from China-Analysis Based on China's Policy of Poverty Alleviation by Education. Science Insights Education Frontiers, 8, 959-973. https://doi.org/10.15354/sief.21.re004

Zhang, Z. Y. (2019). Research on the Poverty Alleviation Path of Library Culture under the Vision of Accurate Poverty Alleviation. Journal of Suihua University, No. 12, 131133. 